\title{
Erratum to: Joseph covariance formula adaptation to Square-Root Sigma-Point Kalman filters
}

\author{
Francesco De Vivo - Alberto Brandl • \\ Manuela Battipede • Piero Gili
}

Published online: 15 February 2017

(C) Springer Science+Business Media Dordrecht 2017

\section{Erratum to: Nonlinear Dyn \\ DOI 10.1007/s11071-017-3356-x}

There was an error in Eq. 43 in the original publication. Unfortunately, an erroneous letter ' $v$ ' was inserted between the + sign and the vector with the $\mathrm{B}$ elements during typesetting. The correct equation is shown below.

$$
\dot{\mathbf{x}}=\left[\begin{array}{ccc}
\mathbf{A}\left(\omega_{c}, \alpha\right) & 0 & 0 \\
0 & \mathbf{A}\left(\omega_{c}, \alpha\right) & 0 \\
0 & 0 & \mathbf{A}\left(\omega_{c}, \alpha\right)
\end{array}\right] \mathbf{x}+\left[\begin{array}{l}
\mathbf{B} \\
\mathbf{B} \\
\mathbf{B}
\end{array}\right] \mathbf{v}_{n-1}
$$

The online version of the original article can be found under doi:10.1007/s11071-017-3356-x.

F. De Vivo $(\varangle)$

Polytechnic of Turin, C.so Duca degli Abruzzi, 24,

10129 Turin, Italy

e-mail: francesco.devivo@polito.it

\begin{abstract}
A. Brandl · M. Battipede · P. Gili Polytechnic of Turin, Turin, Italy e-mail: alberto.brandl@polito.it
\end{abstract}

M. Battipede

e-mail: manuela.battipede@polito.it

P. Gili

e-mail: piero.gili@polito.it 